\title{
Generation and transcriptional programming of intestinal dendritic cells: essential role of retinoic acid
}

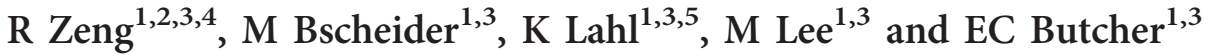

The vitamin A metabolite retinoic acid (RA) regulates adaptive immunity in the intestines, with well-characterized effects on IgA responses, Treg induction, and gut trafficking of T- and B-effector cells. It also controls the generation of conventional dendritic cell $(\mathrm{CDC})$ precursors in the bone marrow and regulates $\mathrm{CDC}$ subset representation, but its roles in the specialization of intestinal CDC subsets are understudied. Here we show that RA acts cell intrinsically in developing guttropic pre-mucosal dendritic cell (pre- $\mu \mathrm{DC}$ ) to effect the differentiation and drive the specialization of intestinal $\mathrm{CD} 103^{+} \mathrm{CD} 11 \mathrm{~b}^{-}$(cDC1) and of CD103 ${ }^{+} \mathrm{CD}_{11 \mathrm{~b}}{ }^{+}$(CDC2). Systemic deficiency or DC-restricted antagonism of RA signaling resulted in altered phenotypes of intestinal $\mathrm{CDC} 1$ and $\mathrm{CDC} 2$, and reduced numbers of $\mathrm{CDC} 2$. Effects of dietary deficiency were most apparent in the proximal small intestine and were rapidly reversed by reintroducing vitamin $A$. In cultures of pre$\mu \mathrm{DC}$ with Flt3L and granulocyte-macrophage colony-stimulating factor (GM-CSF), RA induced cDC with characteristic phenotypes of intestinal $\mathrm{CDC} 1$ and $\mathrm{CDC} 2$ by controlling subset-defining cell surface receptors, regulating subset-specific transcriptional programs, and suppressing proinflammatory nuclear factor- $\mathrm{\kappa B}$-dependent gene expression. Thus, RA is required for transcriptional programming and maturation of intestinal $\mathrm{CDC}$, and with GM-CSF and Flt3L provides a minimal environment for in vitro generation of intestinal CDC1- and CDC2-like CDC from specialized precursors.

\section{INTRODUCTION}

The intestines are continuously challenged by microbiota, digested food and invading pathogens. Intestinal dendritic cells (DC) have a key role in immune homeostasis by directing immune responses appropriate to each antigen and stimulus encountered. DCs have the unique ability to sample and process antigens, and translate microenvironmental cues for $\mathrm{T}$ and $\mathrm{B}$ cells through presentation of cytokines and metabolites to initiate and regulate immune responses or to induce or maintain tolerance.

The two predominant conventional dendritic cell (cDC) subsets in the small intestine (SI) are identified phenotypically as $\mathrm{CD}_{11 \mathrm{c}^{+}} \mathrm{MHCII}^{+}$cells that are either $\mathrm{CD} 103^{+} \mathrm{CD} 11 \mathrm{~b}^{-}$ (hereinafter called $\mathrm{cDC} 1$ ) or $\mathrm{CD}_{103}{ }^{+} \mathrm{CD}_{11 \mathrm{~b}}{ }^{+}(\mathrm{cDC} 2)$. The subsets differ developmentally, requiring different transcription factors. Although both process local antigen, migrate to draining mesenteric lymph nodes (MLN), generate tolerogenic or immune stimulatory responses, and imprint T-cell trafficking to the gut, they also differ functionally: e.g., cDC2 express TLR5 that recognizes flagellin and are better inducers of Th17 cells and of IgA synthesis, and $\mathrm{CDC} 1$ express TLR3, a pattern receptor for double-stranded viral RNA, and display Clec9A and XCR1, receptors implicated in the specialized ability of $\mathrm{CDC} 1$ to crosspresent cell-associated antigens to CD8 T cells in vivo. ${ }^{1-9}$ Both subsets can derive from phenotypically diverse bone marrow (BM) precursors, ${ }^{10,11}$ including pre-mucosal DC (pre- $\left.\mu \mathrm{DC}\right)$, a gut-tropic precursor that can give rise to both $\mathrm{CDC}$ subsets, as well as to plasmacytoid DC. Pre- $\mu$ DC express the gut homing receptor $\alpha 4 \beta 7$, migrate preferentially to the intestinal lamina propria (LP), and efficiently repopulate intestinal $\mathrm{CDC}$ pools.

\footnotetext{
${ }^{1}$ Laboratory of Immunology and Vascular Biology, Department of Pathology, Stanford University School of Medicine, Stanford, California, USA. ${ }^{2}$ Program of Immunology, Stanford University School of Medicine, Stanford, California, USA and ${ }^{3}$ Center for Molecular Biology and Medicine, Veterans Affairs Palo Alto Health Care System, Palo Alto, California, USA. Correspondence: EC Butcher or R Zeng (ebutcher@stanford.edu or Ruizhu.zeng@gmail.com)

${ }^{4}$ Current address: Translational Laboratory in Genetic Medicine (TLGM), 8A Biomedical Grove, Immunos Level 5, Singapore 138648.

${ }^{5}$ Current address: Section for Virology, National Veterinary Institute, Technical University of Denmark, Frederiksberg, Denmark, and Immunology Section, BMC D14, Lund University, Lund, Sweden.
} 
Vitamin A enters the body in the diet and achieves its highest concentrations in the proximal intestines and the draining mesenteric lymph nodes. High concentrations are maintained by bile secretion of retinal from systemic reservoirs, even during short-term deficiency of dietary sources. ${ }^{12}$ Vitamin $\mathrm{A}$ is metabolized by intestinal epithelial, stromal, and DCs to the active form, retinoic acid (RA), which regulates transcription through its nuclear receptors. ${ }^{13} \mathrm{RA}$ is intimately involved in all aspects of intestinal homeostasis, regulating epithelial differentiation and barrier function, as well as the development and function of cells of the innate and adaptive immune system with both immune stimulatory or tolerogenic effects depending on the context. ${ }^{13}$ RAR $\alpha$-dependent RA signaling enhances IgA class switching, ${ }^{14}$ promotes Treg induction, ${ }^{15,16}$ and imprints activated $\mathrm{B}$ and $\mathrm{T}$ cells with gut-trafficking programs by inducing expression of the $\alpha 4 \beta 7$ integrin receptor for the mucosal vascular addressin MAdCAM1, and the chemoattractant receptor CCR9 for the small intestinal chemokine CCL25. ${ }^{14,17}$ RA can also affect DC: it regulates the generation and representation of Notch-dependent $\mathrm{CD} 4^{+}$and $\mathrm{CD} 4{ }^{-}$ CD8 ${ }^{-}$splenic $\mathrm{CDC} ;{ }^{18,19}$ induces DC expression of aldh1a2, a retinaldehyde dehydrogenase that confers on intestinal $\mathrm{CD}_{103}{ }^{+} \mathrm{DC}$ their characteristic ability to produce RA, to present it directly to interacting lymphocytes ${ }^{12,20,21}$ and synergizes with transforming growth factor- $\beta$ to induce a tolerogenic DC phenotype. ${ }^{22}$ Moreover, although RA precursors are most concentrated in the intestines and gutassociated lymphoid tissue, RA is also produced locally from circulating retinol in other sites including the $\mathrm{BM}$ where it enhances production of gut tropic pre- $\mu \mathrm{DC} .^{11}$

Here we sought to determine whether RA also controls the further development of pre- $\mu \mathrm{DC}$, and to examine its contribution to the specialization of intestinal $\mathrm{cDC}$ subsets. Our results show that cell intrinsic RAR $\alpha$ signaling regulates pre$\mu \mathrm{DC}$ generation of intestinal $\mathrm{cDC}$ and has a central role in transcriptional programming of both $\mathrm{CDC} 1$ and of $\mathrm{CDC} 2$. Moreover, we show that in combination with granulocytemacrophage colony-stimulating factor (GM-CSF) and Flt3L, $\mathrm{RA}$ directs efficient in vitro generation of $\mathrm{CDC}$ with unique characteristics of intestinal $\mathrm{cDC} 1$ and $\mathrm{cDC} 2$ from their gut tropic pre- $\mu \mathrm{DC}$ precursors.

\section{RESULTS}

RA signaling in DC controls intestinal CDC development We initially evaluated $\mathrm{CDC}$ in mice rendered vitamin A deficient (VAD) by feeding a VAD diet for 12 weeks starting in utero. ${ }^{17} \mathrm{VAD}$ affected both the phenotypes and representation of intestinal $\mathrm{cDC}$ subsets. The frequency and number of cDC2 $\left(\mathrm{CD} 103^{+} \mathrm{CD}_{11 b^{+}}\right)$was reduced in both SI LP and mesenteric lymph nodes of C57BL/6 mice, compared with mice on a control diet (Figure 1a,b). Similar results were obtained in $\mathrm{BALB} / \mathrm{c}$ mice (Supplementary Figure S1a online) and in C57BL/6 mice fed a VAD diet beginning at weaning (Supplementary Figure S1b). In contrast to the $\mathrm{CD}_{103^{+}}$ cDC subsets, the mixed $\mathrm{CD}_{103}{ }^{-} \mathrm{CD}_{11 \mathrm{~b}}{ }^{+}$population, which consists of macrophages and minor $\mathrm{CD}_{103}{ }^{-}$intestinal $\mathrm{cDC}$ populations, although variable in numbers and frequency, showed no consistent difference between control and VAD mice in our studies (data not shown). Critical evaluation of the effect of RA on macrophage development will require studies with additional macrophage's markers.

Moreover, the phenotype of $\mathrm{CDC}$ was abnormal in VAD mice (Figure 1c): $\mathrm{cDC1}$ in VAD SI expressed only low levels of the cDC1-specific pathogen recognition receptor TLR3, but as reported $^{23}$ displayed upregulated CD207 (Langerin), a lectin receptor expressed by skin-associated DC such as Langerhans cells and dermal $\mathrm{DC}^{24}$ but normally absent on intestinal DC. In contrast, cDC2 in VAD mice lacked CD101, an immunoregulatory receptor characteristic of $\mathrm{CDC} 2$ in normal (vitamin $\mathrm{A}$ sufficient) mice. RA and precursor concentrations are highest in the proximal SIs, ${ }^{12,25,26}$ where $\mathrm{CDC} 2$ predominate. ${ }^{27}$ Consistent with the role of RA in generating $\mathrm{cDC} 2$, vitamin A deficiency largely abolished the proximal to distal gradient in relative representation of the $\mathrm{CDC} 2$ and $\mathrm{CDC} 1$ populations (Figure 1d). Moreover, the effects of VAD were reversible: 1 week of dietary vitamin A had little impact, but after 2 weeks the phenotype (e.g., expression of CD101) and relative representation of CDC2 (ratio to $\mathrm{CDC} 1$ ) in previously long-term $\mathrm{VAD}$ mice had returned to that of control animals (Figure 1e and data not shown). The time required for reconstitution of intestinal $\mathrm{CDC} 2$ is consistent with their reported half-life of 1-2 weeks, ${ }^{28}$ suggesting that RA might affect subset development from precursors. Indeed, VAD decreased the generation of $\mathrm{cDC} 2$ from transferred pre- $\mu \mathrm{DC}$ precursors, as indicated by the decreased ratio of $\mathrm{CDC} 2$ to $\mathrm{CDC} 1$ among the recovered progeny in adoptive recipients (Figure 1f). These results suggest that RA acts locally on recruited precursors to influence their differentiation into one subset or the other, although an effect on pre- $\mu \mathrm{DC}$ homing or on differential survival or retention of progeny $\mathrm{CDC}$ subsets was not excluded. Mice treated with the selective RAR $\alpha$ agonist AM580 displayed an increased ratio of $\mathrm{CDC} 2$ to $\mathrm{CDC} 1$ in the SI LP, mirroring the effects of atRA supplementation (Figure 1g) and suggesting that $R A$ affects $c D C$ differentiation via RAR $\alpha$ signaling. In contrast, the pan-RAR antagonist BMS493 decreased the ratio of $\mathrm{CDC} 2$ to cDC1 (Figure 1g).

RA affects multiple cell types in the gut, including stromal cells and the epithelium, and could affect cDC indirectly. To determine whether DC-intrinsic RAR signaling was involved, we engineered mice to express a dominant-negative RAR $\alpha$, RAR403, under the control of the CD11c promoter by crossing CD11c-Cre mice to mice carrying RAR403 downstream of a loxP-flanked STOP cassette (dnRara $\left.{ }^{\text {lsl/lsl }}\right){ }^{29}$ These "DCRAR403 mice" had a significant reduction in both absolute cDC2 numbers and in the $\mathrm{CDC} 2 / \mathrm{cDC} 1$ ratio in the SI LP and mesenteric lymph nodes compared with their wild-type (WT) littermates (Figure 2a) and these effects were more prominent in mice that had two copies of the RAR403 gene (DC-RAR403 $3^{f l / f l}$ ) compared with mice with one copy (DC-RAR403 $3^{f l-}$ ). As in VAD mice, a subpopulation of intestinal cDC1 cells in DC-RAR403 mice expressed CD207 (Langerin) (Figure $\mathbf{2 b}$ ). The results suggest that RA acts cell 

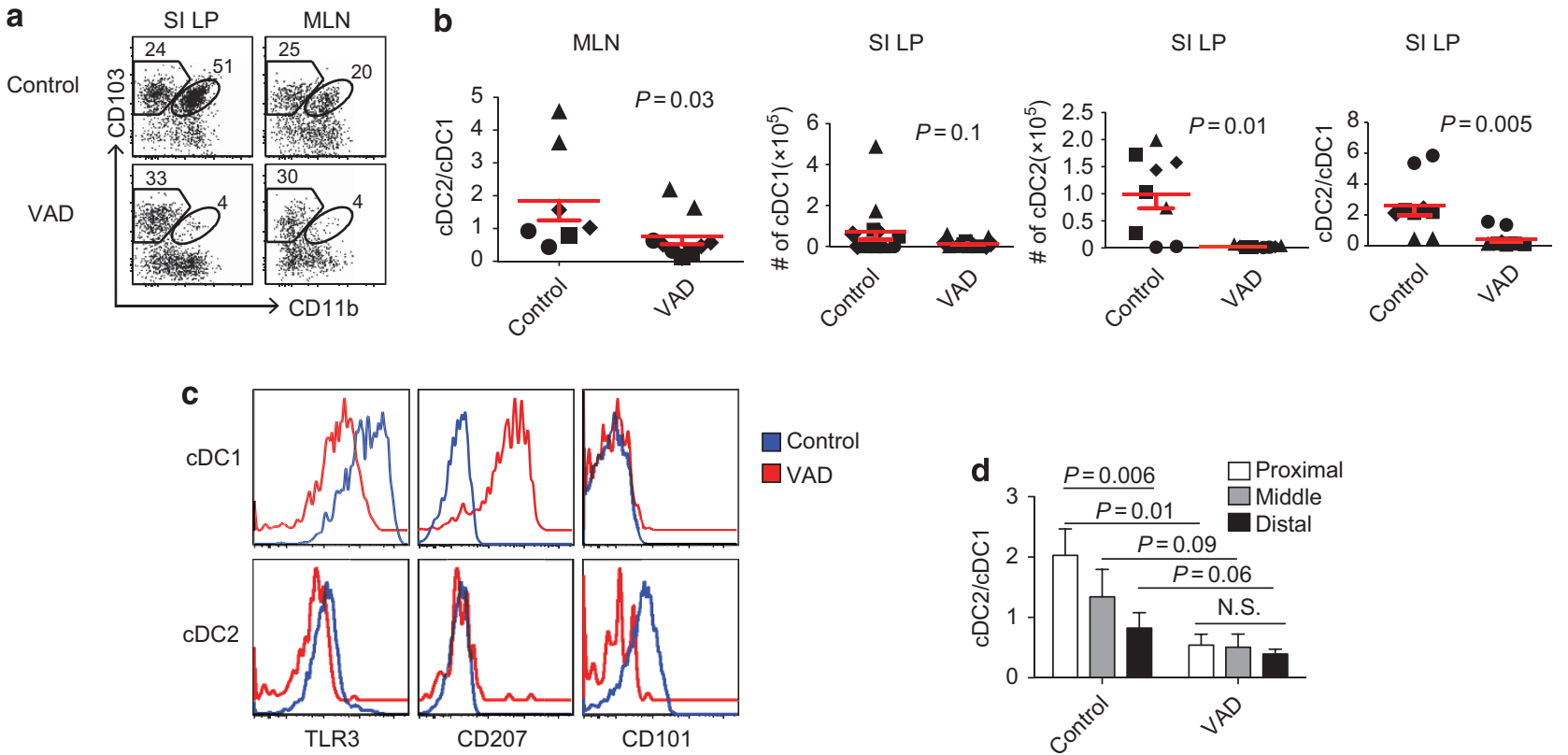

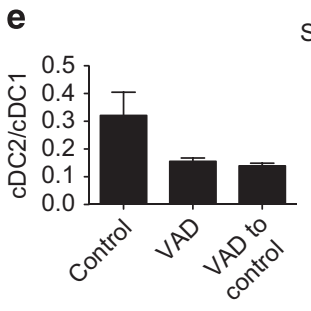

7 days after diet change

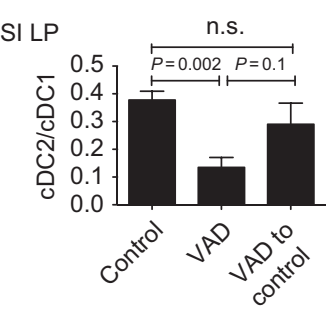

14 days after diet change

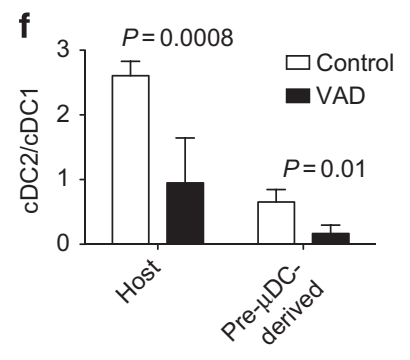

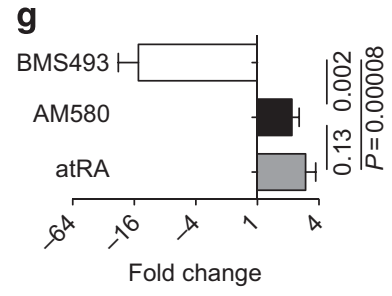

$(\mathrm{CDC} 2 / \mathrm{CDC} 1$ in treated $\mathrm{SI})$

/ (cDC2/cDC1 in control SI)

Figure 1 Vitamin A deficiency decreases CDC2 in gut-associated lymphoid tissue (GALT). (a) fluorescence-activated cell sorting (FACS) plots show subset composition of $\mathrm{CD} 11 \mathrm{c}^{+} \mathrm{MHClI}^{+} \mathrm{CDC}$ in the small intestine (SI) lamia propria (LP) and MLN from control and long-term VAD mice. The number in each gate indicates percent of cells. (b) Ratio of CDC2 to CDC1 in MLN and SI LP, numbers of CDC1 and cDC2 recovered from SI LP of control, and vitamin A-deficient (VAD) mice. Paired two-tailed t-test. Error bars show s.e.m. (c) TLR3, CD207, and CD101 expression on SI cDC1 and cDC2 from control and VAD mice. (d) Effects of VAD on cDC subsets in different segments of the SI. SI from control and VAD animals were divided into three equal segments. $N=4$ independent experiments, three mice each. Paired one-tailed $t$-test. (e) Long-term VAD BALB/c mice were put on vitamin A-sufficient diet for 7 or 14 days. Results for 7 days were from two animals in each group from one experiment; results for 14 days were pooled from three independent experiments with two to three animals per condition in each experiment. (f) Sorted pre-mucosal dendritic cell (pre- $\mu \mathrm{DC} ; 0.5-1 \times 10^{6}$ ) were adoptively transferred intravenously into control or VAD recipients and mice were killed 6 or 7 days later. Histograms show ratios of host or pre- $\mu D C$-derived SI cDC2 to $c D C 1$.Unpaired one-tailed $t$ test. (g) Pharmacological agonists of RAR, atRA, and AM580 increased and antagonist BMS493 decreased the cDC2/cDC1 ratio in the SI of BALB/c mice. Fold change (FC) of the ratio of $\mathrm{CDC} 2$ to $\mathrm{CDC} 1$ in SI LP from treated vs. control animals. Results for each condition are pooled from two independent experiments with three animals each. Unpaired one-tailed $t$-test. CDC, conventional dendritic cell; MLN, mesenteric lymph nodes; NS, not significant.

intrinsically in intestinal $\mathrm{cDC} 1$ and $\mathrm{cDC} 2$, to influence their phenotype and development. However, subsets of intestinal macrophages are reported to exhibit cre recombination in CD11ccre mice ${ }^{30}$ and may express RAR403 in our model; thus, indirect effects of macrophages on CDC phenotypes cannot be excluded.

Splenic cDC were also affected in DC-RAR403 mice (Supplementary Figure S2). As in the SI of DC-RAR403 mice, a subset of splenic $\mathrm{CD} 8 \alpha^{+} \mathrm{CDC} 1$ in DC-RAR403 mice but not in WT controls expressed Langerin (CD207) (Supplementary Figure S2a). Both $\mathrm{CD}_{11} \mathrm{~b}^{+}$and $\mathrm{CD} 8 \alpha^{+} \mathrm{cDC}$ numbers were diminished in the spleen of DC-RAR403 mice, but the ratio of $\mathrm{CD} 11 \mathrm{~b}^{+} \mathrm{cDC}$ to $\mathrm{CD} 8 \alpha^{+} \mathrm{cDC}$ was unchanged compared with WT littermates (Supplementary Figure S2b and data not shown). However, cDC expressing Clec4a4 (DCIR2, recognized by Mab 33D1, a classical cDC2 marker) were significantly reduced, resulting in a reduced Clec4a4-defined $\mathrm{cDC} 2$ to $\mathrm{cDC} 8 \alpha^{+} \mathrm{cDC1}$ ratio (Supplementary Figure S2c). The $\mathrm{Clec} 4 \mathrm{a}^{+}{ }^{+}$subset that is strongly reduced in numbers in DCRAR403 mice also expressed Esam in WT mice (Supplementary Figure S2d). Thus, cell-intrinsic RAR signaling influenced both CDC1 and $\mathrm{CDC} 2$ in the spleen as well as in the SI.

Together the results suggest that DC-intrinsic RAR signaling regulates the development and phenotypic specialization of cDC subsets in both intestinal and extraintestinal sites, but support a particularly important role for RA in determining intestinal $\mathrm{CDC}$ phenotypes and regional specialization in the proximal SIs and draining mesenteric lymph nodes where RA concentrations are high. 

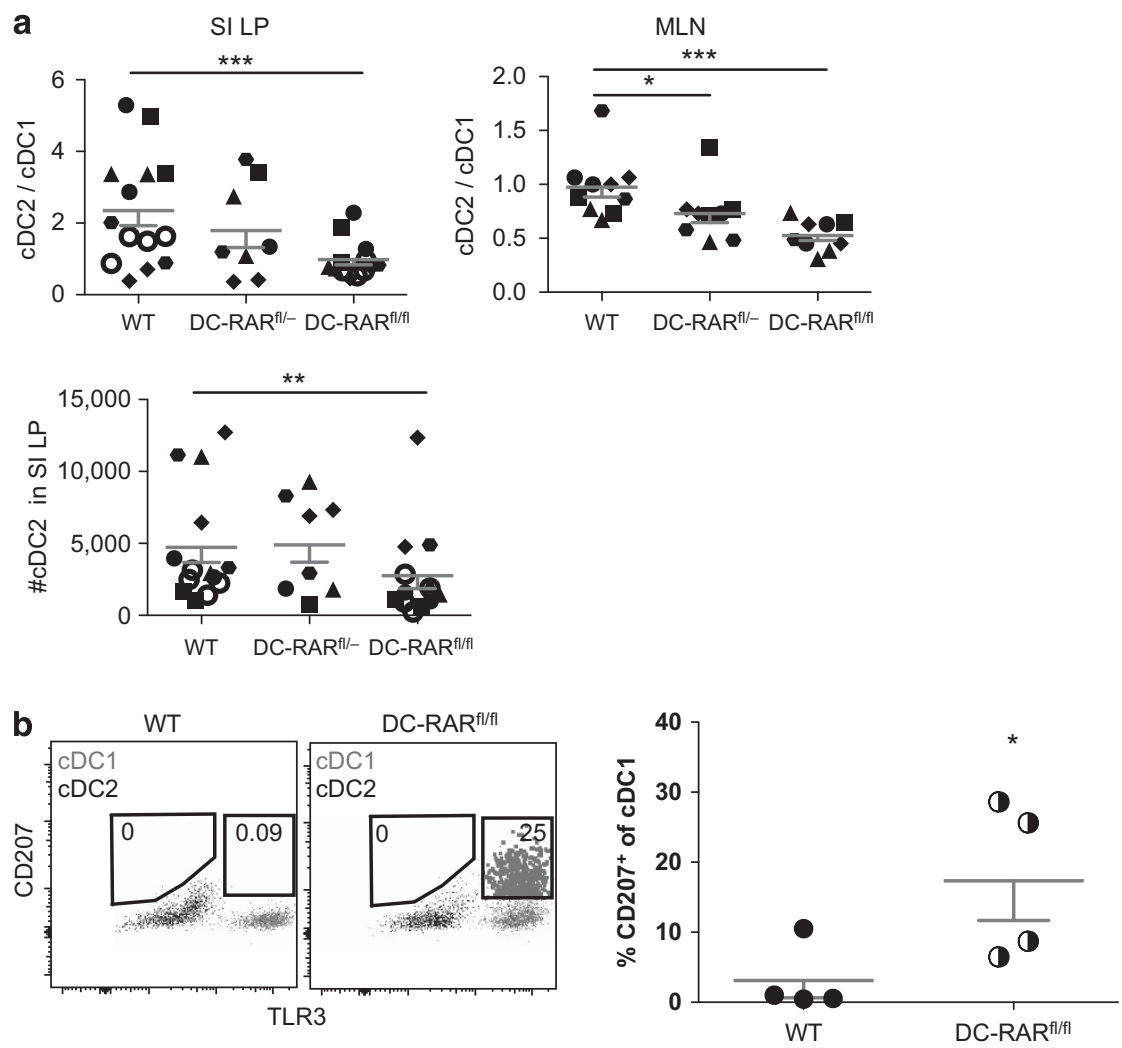

Figure 2 Effects of dendritic cell (DC)-restricted deficiency in retinoic acid (RA) signaling on small intestine (SI) DC. (a) Ratio of cDC2 to cDC1 in SI lamina propria (LP) and MLN and number of CDC2 in SI LP from DC-RAR403 ${ }^{-1-}$ (wild type (WT)), DC-RAR403 $3^{\mathrm{tl} /}$ - (heterozygous) and DC-RAR403 ${ }^{\mathrm{t} / \mathrm{fl}}$ (homozygous) mice. (b) Aberrant expression of CD207 on SI cDC1 from DC-RAR403 mice. Shown are representative plots illustrating CD207 expression cells by SI cDC1 from DC-RAR ${ }^{\mathrm{fl} / \mathrm{fl}}$ mice (cells inside $\mathrm{CD} 207^{+}$gates are displayed as large dots for illustration). Scatter plot shows the percentage of CDC1 in SI that express CD207. Unpaired one-tailed $t$-test. cDC, conventional dendritic cell; MLN, mesenteric lymph nodes.

\section{RA directs generation of intestine-like $\mathrm{CDC} 1$ and $\mathrm{CDC2}$ subsets in vitro}

Although a variety of culture conditions have been used to generate DC from BM or monocyte precursors, classical culture conditions lead to DC whose phenotypes correspond poorly to those of intestinal $\mathrm{cDC}$ subsets observed in vivo. ${ }^{31-33} \mathrm{We}$ evaluated the phenotype of pre- $\mu \mathrm{DC}$ progeny generated in vitro. GM-CSF and Flt3L have been implicated in intestinal DC development: Flt3 KO mice have a global reduction in $\mathrm{CD} 103^{+} \mathrm{cDC}$ in the SI, whereas csf2r deficiency (GM-CSF receptor) selectively affects $\mathrm{CDC} 2$ numbers ${ }^{34}$ and leads to poor DC expression of retinaldehyde dehydrogenase activity. ${ }^{21}$ However, pre- $\mu \mathrm{DC}$ cultured with Flt3L alone developed into $\mathrm{CD} 103^{+} \mathrm{CD}_{11 \mathrm{~b}}{ }^{-}$and $\mathrm{CD} 103^{-} \mathrm{CD}_{11} \mathrm{~b}^{+}$cells, but not $\mathrm{CD} 103^{+} \mathrm{CD}_{11 \mathrm{~b}}{ }^{+} \mathrm{cDC} .{ }^{11}$ Culture of pre- $\mu \mathrm{DC}$ with Flt3L and GM-CSF gave rise to $\mathrm{CD} 103^{+} \mathrm{CD}_{11 \mathrm{~b}}{ }^{-}$and $\mathrm{CD} 103^{+} \mathrm{CD} 11 \mathrm{~b}^{+}$ DCs (Figure 3a), but these DC lacked or displayed inappropriate expression of functionally important markers that define normal intestinal $\mathrm{cDC} 1$ and $\mathrm{cDC} 2$ in vivo. For instance, without RA in-vitro-derived CDC1 lacked TLR3 and had reduced Clec9a, whereas cDC2 lacked CD101 expression (Figure 3a). cDC1 derived in vitro without RA also aberrantly expressed CD207. Interestingly, these features (reduced TLR3 and expression of $\mathrm{CD} 207$ on $\mathrm{CDC} 1$, and the absence of
CD101 by cDC2 generated without RA) parallel the phenotypic abnormalities observed in VAD mouse intestinal $\mathrm{CDC}$ (Figure 1c). Moreover, $\mathrm{CDC} 1$ and $\mathrm{CDC} 2$ generated without RA lacked retinaldehyde dehydrogenase expression as indicated by lack of staining in the Aldefuor assay (Figure 3a).

Addition of RA, however, led to the generation of $\mathrm{CDCl}$ and cDC2 with key phenotypic features of the two intestinal cDC subsets, including TLR3 on $\mathrm{CDC} 1$ and CD101 on CDC2, as well as retinaldehyde dehydrogenase expression by both subsets (Figure 3a). These results suggest that GM-CSF, Flt3L and RA act cooperatively to provide critical signals required for differentiation of intestinal $\mathrm{cDCs}$ from $\mathrm{BM}$ precursors. RA regulation of $\mathrm{Clec} 9 \mathrm{a}$ on $\mathrm{CDC} 1$ and $\mathrm{CD} 101$ expression on the cDC2 subset was dose dependent (Figure 3b).

RA effected an increase in CDC2 in vitro, similar to its effect in vivo. When pre- $\mu \mathrm{DC}$ were cultured with varying concentrations of RA or the RAR $\alpha$ agonist AM580 for 4 days, the presence of RA or AM580 increased the number of $\mathrm{CDC} 2$ generated while decreasing $\mathrm{CDC1}$ numbers, effectively increasing the $\mathrm{CDC} 2 / \mathrm{cDC} 1$ ratio. The effect of RA was dose dependent, with the $\mathrm{cDC} 2 / \mathrm{cDC} 1$ ratio increasing from 0 to $1 \mathrm{~nm} \mathrm{RA}$ and plateauing as the RA concentration reached levels reported for the $\mathrm{SI}^{25}(\sim 10 \mathrm{nM})$. As the total number of progeny cells was not affected by RA or AM580 (Figure 3c), the results are consistent 


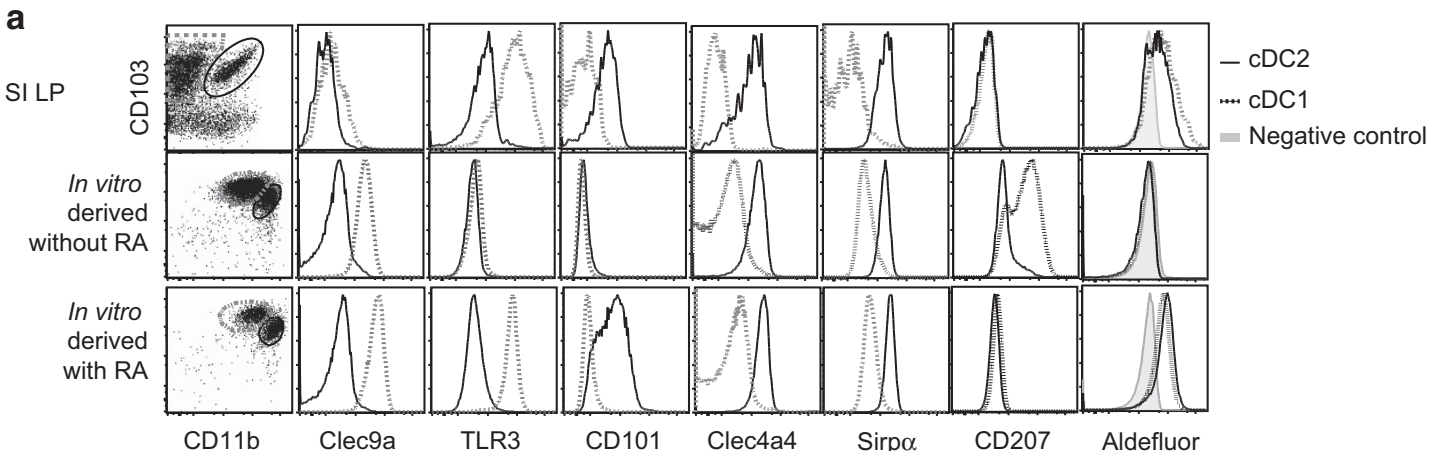

b

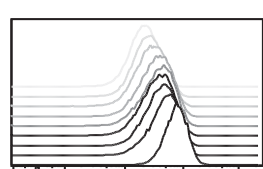

Clec9a

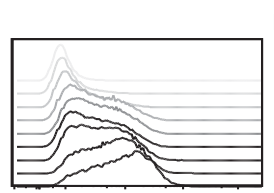

CD101
RA concentration

$0 \mathrm{nM}$

$0.0625 \mathrm{nM}$

$-0.125 \mathrm{nM}$

$-0.25 \mathrm{nM}$

$-0.5 \mathrm{nM}$

$-1 \mathrm{nM}$

$-10 \mathrm{nM}$

$-100 \mathrm{nM}$

$-1,000 \mathrm{nM}$
C
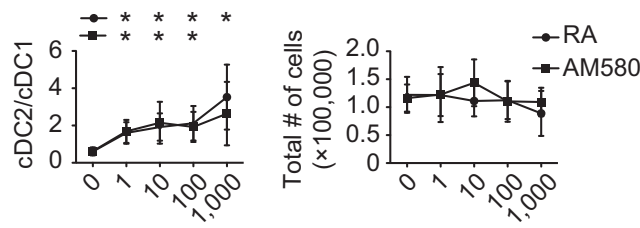

若

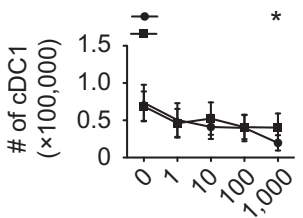

RA concentration (nM)

Figure 3 Retinoic acid (RA) directs generation of intestinal cDC-like dendrictic cell (DC) subsets in vitro. (a-c) Pre-mucosal DCs (pre- $\mu$ DCs) were sorted from the BM of FIt3L-injected mice and cultured in complete Iscove's modified Deulbecco's media with $10 \%$ delipidated serum supplemented with Flt3L and granulocyte-macrophage colony-stimulating factor (GM-CSF) without or with $100 \mathrm{nM}$ of RA (or AM580 in c) unless otherwise specified. Cultures were collected on day 4 and analyzed by flow cytometry. (a) Surface markers and retinaldehyde dehydrogenase (RALDH) activity indicated by AldeFluor staining on in vivo intestinal and in vitro-derived CDC1 (dotted line) and CDC2 (solid line) are shown. Representative of at least three independent experiments. (b) Expression of Clec9a on in-vitro-derived CDC1 and of CD101 on cDC2 with varying RA concentration. Representative of two independent experiments. (c) Ratio of $\mathrm{CDC} 2$ to $\mathrm{CDC} 1$, numbers of total progeny cells and numbers of $\mathrm{CDC} 1$ and $\mathrm{CDC} 2$ in cultures treated with indicated concentrations of RA or AM580 are shown. Data are pooled from three independent experiments. cDC, conventional dendritic cell.

with direct action of RA on RAR $\alpha$ in DC precursors to influence their fate.

Together, the results suggest a critical cell-intrinsic role for RA in intestinal $\mathrm{CDC}$ specialization and define culture conditions for modeling of intestinal $\mathrm{cDC}$ development.

\section{RA drives the transcriptomes of in-vitro-derived $\mathrm{CDC} 1$ and cDC2 toward physiologic patterns of gene expression}

To assess the effects of RA on transcriptional programming of differentiating $\mathrm{CDC}$, we carried out whole-genome expression analyses on sorted pre- $\mu \mathrm{DC}$, and on $\mathrm{CDC} 1$ and $\mathrm{CDC} 2$ generated from pre- $\mu \mathrm{DC}$ during a 5-day culture with Flt3L and GM-CSF, with or without $100 \mathrm{~nm}$ RA. Expression profiles of the SI and the spleen cDC1 and cDC2 (ref. 35; from http://immgen.org, GEO accession number GSE15907) were included for comparison. Principal component analysis using all expressed genes (raw expression values $>120$ and a coefficient variance of $<50 \%$ in at least half of the samples) showed clustering of samples by cell type, indicating low technical and biological variation (Supplementary Figure S3). To assess the effects of RA on expression of genes associated with $\mathrm{CDC} 1$ vs. cDC2 specialization, we focused on a set of 1,200 genes with 2-fold different expression between SI cDC1 and $\mathrm{cDC} 2$, and/or between the spleen
$\mathrm{cDC} 2\left(\mathrm{CD} 8 \alpha^{-\mathrm{CD}} 4{ }^{+} \mathrm{CD} 11 \mathrm{~b}^{+} \mathrm{cDC}\right)$ and $\mathrm{cDC} 1\left(\mathrm{CD} 8 \alpha^{+} \mathrm{CD} 4^{-}\right.$ $\left.\mathrm{CD} 11 \mathrm{~b}^{-} \mathrm{cDC}\right)$. Principal component analysis using these cDC1- and $\mathrm{cDC} 2$-associated gene sets revealed that $\mathrm{CDC}$ generated without RA remained distant from their in vivo counterparts (Figure 4a). In contrast, when generated in the presence of RA, CDC1 and to some extent $\mathrm{CDC} 2$ clustered more closely to their in vivo counterparts. In direct comparison of correlation of gene expression with SI cDC, in-vitro-derived cDC1 aligned with SI CDC1 and their gene expression profile displayed a significantly higher correlation with that of SI cDC1 in vivo when RA was present during their development (Figure 4b,c). Similarly in-vitro-derived cDC2 displayed significant correlation in gene expression with SI cDC2 and the presence of RA again resulted in a higher correlation with in vivo gene profiles (Figure $\mathbf{4 b}, \mathbf{c}$ ). Both populations derived in vitro with RA aligned more closely with their SI cDC counterparts than with spleen cDC (Figure $\mathbf{4 b}, \mathbf{c}$ ).

To evaluate patterns of gene regulation, we selected 127 genes regulated in vitro by RA ( $>3$-fold different expression by in-vitro-derived $\mathrm{CDC} 1$ with or without RA, or between $\mathrm{CDC} 2$ with or without RA) that also differed at least 3-fold between SI $\mathrm{cDC} 1$ vs. $\mathrm{cDC} 2$ and/or between spleen $\mathrm{cDC} 1$ vs. $\mathrm{cDC} 2$ (Supplementary Table S1 and Figure 4d). These genes could 
be divided into five main clusters based on the effects of RA on their expression (Figure 4d). Cluster I consisted of genes that are higher in both SI and spleen $\mathrm{CDC} 1$ than in $\mathrm{CDC} 2$, and that were induced or maintained (from basal pre- $\mu \mathrm{DC}$ expression values) by RA in in-vitro-derived $\mathrm{CDC} 1$ but not $\mathrm{CDC} 2$, making the expression pattern of this group of genes in the in-vitroderived subsets more similar to their in vivo counterparts.
Functionally important genes in this cluster included Clec $9 a$, Xcr1, TLR3, and CXcr3 encoding the chemokine receptor CXCR3. Genes in cluster II were more highly expressed in $\mathrm{CDC} 2$, especially in $\mathrm{CDC} 2$ from the SI, and were induced by $\mathrm{RA}$ in developing $\mathrm{CDC} 2$. However, RA also inappropriately induced the expression of some of these genes in cDC1. Examples of cluster 2 genes included CD209a, a c-type lectin

a

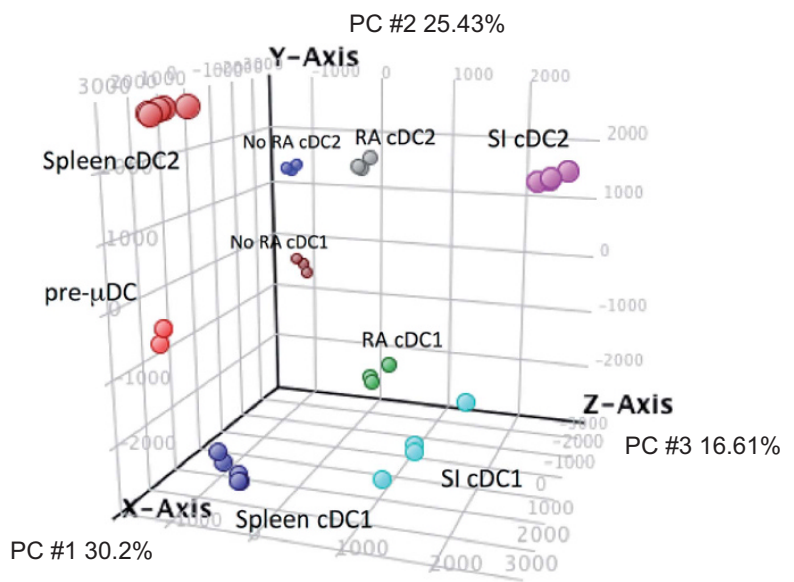

b

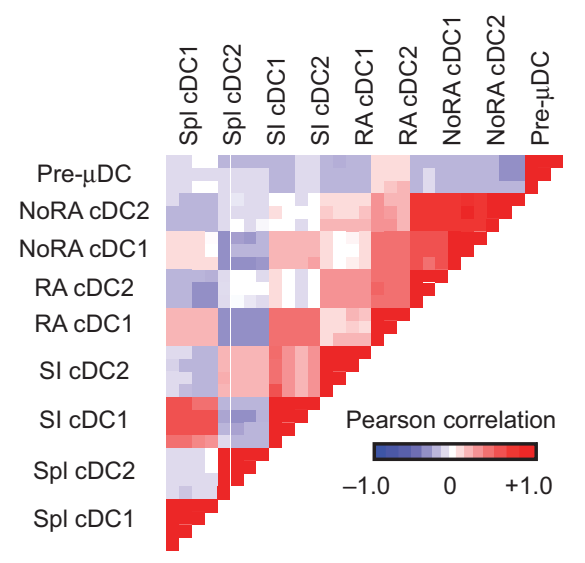

C

vs. Small intestinal $\mathrm{cDC} 2$

vs. Small intestinal cDC1
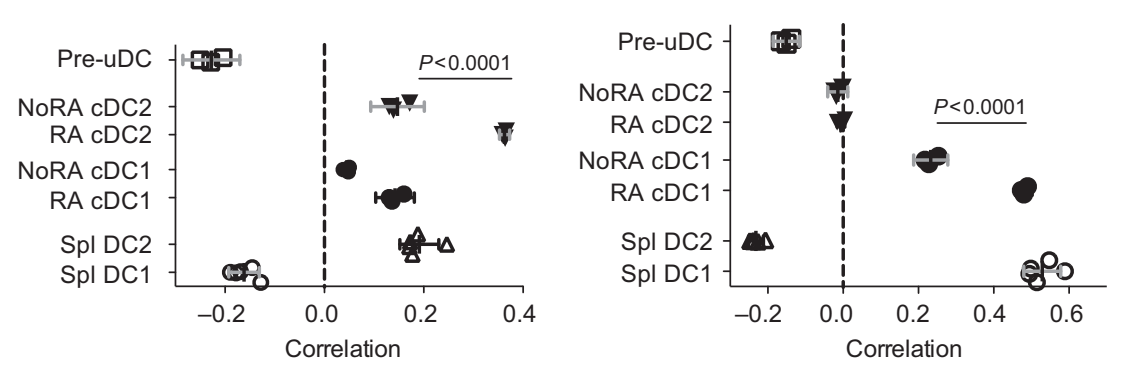

Figure 4 Retinoic acid (RA) drives the transcriptomes of in-vitro-derived cDC1 and cDC2 towards patterns of physiologic gene expression. (a) Principal component analysis (PCA) of pre-mucosal dendritic cell (pre- $\mu \mathrm{DC}$ )-derived $\mathrm{CDC} 1$ and $\mathrm{cDC} 2$ generated in vitro in the presence or the absence of RA, and spleen and small intestine (SI) CDC using 1,200 genes with expression value (EV) $>120$ that differed at least two-fold between SI and/or spleen cDC1 and cDC2. (b) Pairwise comparison of the indicated cDC subsets and bone marrow (BM) pre- $\mu \mathrm{DC}$ using the same genes as in a) (c) Pairwise correlation of gene expression by in-vitro-derived $\mathrm{CDC} 1$ and $\mathrm{cDC} 2$ or spleen $\mathrm{CDC} 1$ and $\mathrm{CDC} 2$ replicates with the mean gene expression profiles of $\mathrm{SI} \mathrm{cDC} 1$ or $\mathrm{CDC} 2$, using the same genes as in a. Error bars are $95 \%$ confidence interval. (d) Heatmap of genes that are differentially expressed ( $>3 \times$ fold change (FC)) between SI or spleen $\mathrm{CDC} 1$ and $\mathrm{CDC} 2$, and regulated by $\mathrm{RA}$ ( $>3 \times \mathrm{FC}$ between in vitro $\mathrm{CDC} 1$ derived with and without $\mathrm{RA}$ or $\mathrm{CDC} 2$ with and without RA). Clustering of genes is based on correlation. (e) Transcription factor expression. Shown is expression of transcription factors implicated previously in dendritic cell (DC) development, or regulated (two FC) by RA in vitro and also differently and coordinately expressed by spleen and SI cDC1 vs. CDC2 (at least $1.5 \mathrm{FC}$ in both SI and spleen). TF implicated in CDC1 or CDC2 development are highlighted in green or red, respectively. cDC, conventional dendritic cell. 
d

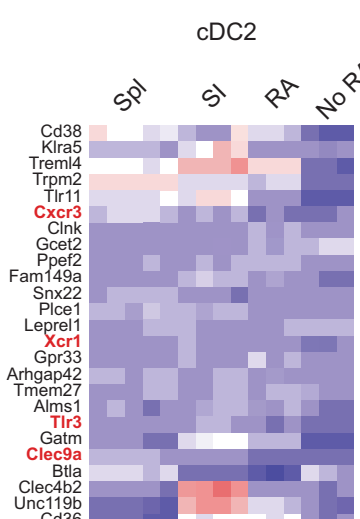

E33002

$$
330020
$$$$
\begin{aligned}
\mathrm{Cd} 36 \\
\mathrm{C}+122 \mathrm{~b}
\end{aligned}
$$$$
\text { A530064 }
$$

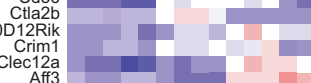$$
\begin{array}{r}
\text { Met } \\
\text { Cacna1e } \\
\text { Fcta }
\end{array}
$$

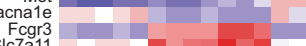

SIc7a11
Ptgs2
Ptose

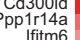

$\mid$ fitm6
$|1| 1 \mid 12$

Fgfr1
Pilirb2
Pilrb1

Pirb1
Pira
DirRik

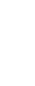

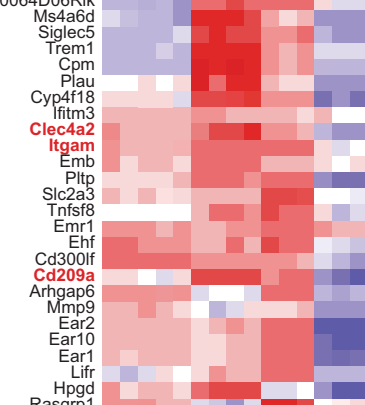

Hpgd
Rasgrp1
Gbo4
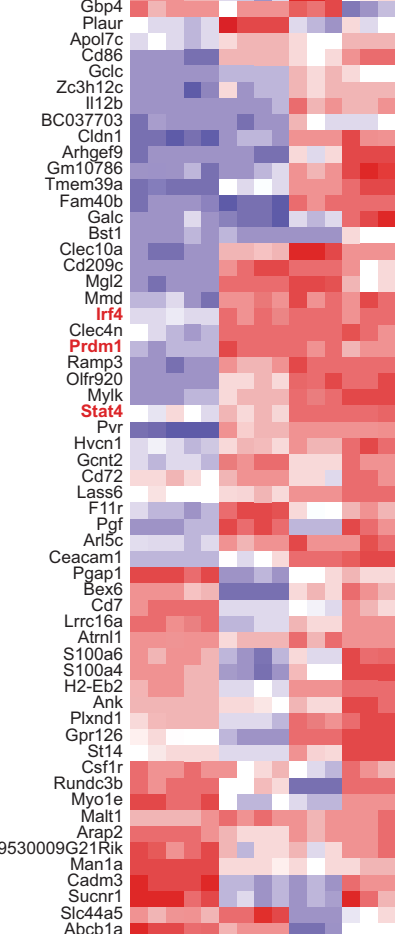

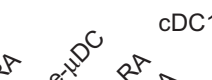
को के

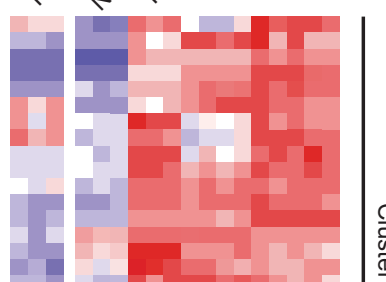

$\frac{O}{\bar{E}}$
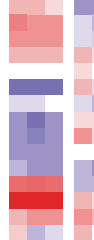

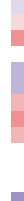

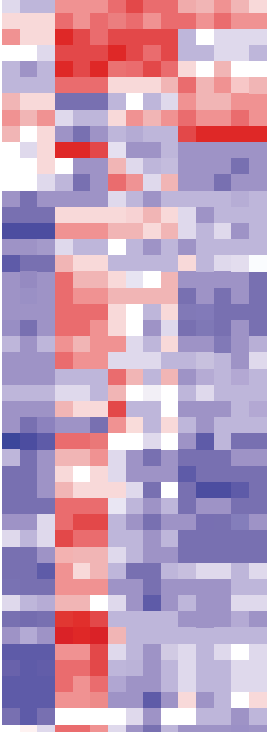

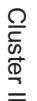

$=$
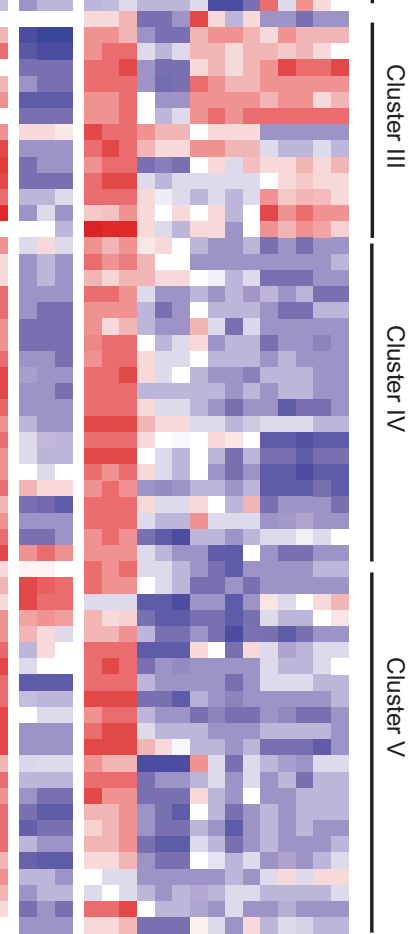

e

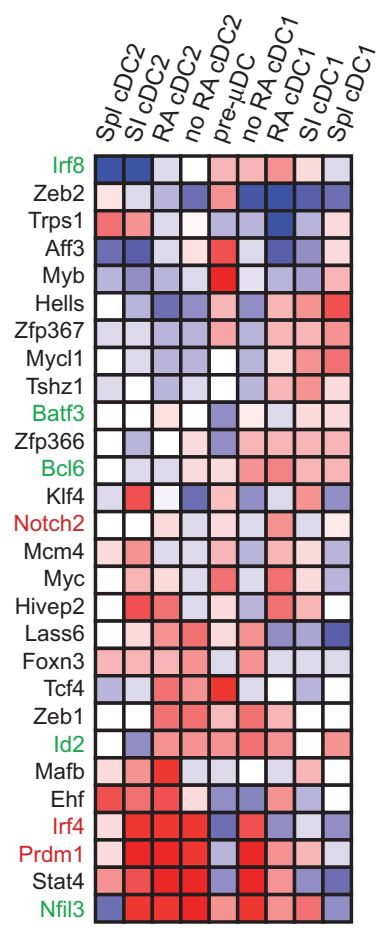

$-2.89$

0.00

2.89

Figure 4 Continued. 
receptor that has been implicated in pathogenic Th17 development in murine schistosomiasis; Itgam, which encodes CD11b; and Clec4a2, a C-type lectin family regulatory receptor. ${ }^{36}$ Cluster III genes were more highly expressed in $\mathrm{CDC1}$ in vivo, but in most cases were actually suppressed in developing $\mathrm{CDC} 1$ by RA: these genes must be programmed by additional factors or conditions not replicated in our in vitro culture conditions. Cluster IV genes were more highly expressed in SI cDC2 than in cDC1 but were not differentially expressed between spleen $\mathrm{CDC1}$ and $\mathrm{cDC} 2$. Interestingly, RA suppressed expression of most of these $\mathrm{CDC} 2$-specific genes in $\mathrm{CDC} 1$ without affecting their expression in $\mathrm{CDC} 2$. Genes in this category included genes for transcription factors important in intestinal cDC2 development (see below). Cluster $\mathrm{V}$ genes were more highly expressed in spleen $\mathrm{CDC} 2$ than in $\mathrm{CDC} 1$, but were not as differentially expressed between the two SI cDC subsets. RA suppressed expression of these genes in $\mathrm{CDC} 2$ and more in cDC1. Together the results show that RA regulates gene expression in both $\mathrm{CDC} 1$ and $\mathrm{cDC} 2$ lineages, acting in a subsetspecific manner to influence their specialization. For the majority of genes, regulation by RA leads to patterns of subset expression that better mimics expression by in vivo subsets, in particular $\mathrm{cDC}$ of the SIs.

\section{RA controls expression of transcription factors involved in cDC differentiation}

We next evaluated expression of selected genes encoding regulators of DNA-templated transcription (Gene Ontology term 0006355) that have either been implicated previously in DC development, or that were regulated (twofold different expression) by RA in vitro and are also differently and coordinately expressed by spleen and SI cDC1 vs. cDC2 (at least $1.5 \mathrm{FC}$ in both the SI and the spleen). RA regulated several genes required for cDC2 development (highlighted in red in Figure 4e): it upregulated Notch2 in developing $\mathrm{cDC} 1$ and in $\mathrm{CDC} 2$ (compared with pre- $\mu \mathrm{DC}$ progeny in cultures without RA) and downregulated Prdm1 and Irf4 in cDC1. RA also downregulated Foxn3 in cDC1. Foxn3, Prdm1 and Irf4 are three of only five transcription factors whose expression was identified as coordinately higher in both human and mouse intestinal cDC2 compared with $\mathrm{cDC} 1$, the other two being Zeb2 and Hivep2. ${ }^{37}$ Zeb2, highest in pre- $\mu \mathrm{DC}$, was maintained or upregulated (compared with pre- $\mu \mathrm{DC}$ progeny in cultures without RA) by RA selectively in $\mathrm{CDC} 2$, correlating with high expression in cDC2 in vivo as well. Hivep2 was upregulated by RA preferentially in cDC2, although RA also enhanced Hivep2 expression in developing $\mathrm{CDC} 1$ in vitro. Among genes required for $\mathrm{cDC1}$ development, RA upregulated Bcl6 in $\mathrm{cDC1}$ and repressed it in $\mathrm{CDC} 2$; however, it had no significant effect on expression of $I d 2$, Irf8, or Batf3. The results suggest a significant role for RA in the regulation of subset-associated TF expression in developing $\mathrm{cDC}$.

\section{Overrepresentation of NF-кB/REL binding sites in promoters of RA suppressed genes}

RA commonly activates gene expression, yet RA treatment suppressed the expression of many genes otherwise induced or expressed in our culture model. We used Enrichr ${ }^{38}$ to identify overrepresented transcription factor binding motifs in the promoter regions of genes whose expression was twofold lower in RA-treated vs. control cDC1 cells: the highest scoring were nuclear factor $-\kappa \mathrm{B}(\mathrm{NF}-\kappa \mathrm{B})$ and REL TFBS (TRANSFAC and JASPAR pwm module, $P \leq 10^{-20}$ and $<10^{-12}$, respectively (see below)). Genes downregulated by RA in $\mathrm{cDC1}$ were also significantly enriched in genes involved in $\mathrm{NF}-\kappa \mathrm{B}-$ mediated pro-inflammatory signaling pathways (Wikipathways, $P=0.00004)$. NF- $\kappa \mathrm{B}$ motifs were also enriched in promoters of RA-suppressed (twofold or more) genes in differentiating $\mathrm{CDC} 2$ (TRANSFAC and JASPAR pwm module; $\left.P<10^{-9}\right)$. Thus, in addition to its role in enhancing $\mathrm{CDC} 2$ generation, under in vitro conditions that support differentiation of $\mathrm{cDC} 1$ and $\mathrm{cDC} 2$, RA suppresses pro-inflammatory gene programs.

\section{DISCUSSION}

We evaluated the role of RA and RAR signaling in the generation and transcriptional programming of intestinal specialized $\mathrm{CDC}$ subsets from gut-tropic BM precursors both in vivo and in a novel in vitro model of the development of $\mathrm{CDC} 1$ and cDC2. Our results indicate that RA acts cell intrinsically to exert global effects on gene expression in both $\mathrm{cDC} 1$ and cDC2 lineages, and drives transcriptional programs that control subset generation and expression of functional and phenotypic features that define intestinal $\mathrm{CDC} 1$ and $\mathrm{CDC} 2$ specialization in vivo.

The combination of Flt3L, GM-CSF and RA was sufficient to drive the in vitro development of gut-tropic pre- $\mu \mathrm{DC}$ into $\mathrm{CD}_{103}{ }^{+} \mathrm{cDC} 1$ and $\mathrm{CDC} 2$ that were similar in cell surface receptor expression to the two subsets found in the gut wall. Mayer et al. ${ }^{32}$ showed that Flt3L and GM-CSF together support development of IRF8- and Batf3-dependent $\mathrm{CD}_{103}{ }^{+} \mathrm{cDC}$, but we found pre- $\mu \mathrm{DC}$-derived $\mathrm{CDC} 1$ generated in the absence of RA had an aberrant cell surface phenotype and were less aligned with intestinal $\mathrm{CDC1}$ in gene expression than $\mathrm{CDC1}$ generated with all three factors. Moreover, culture with RA allows generation of both intestinal DC-like populations. Consistent with our observations in VAD mice, increasing RA concentrations to within the range reported in the proximal SI $(\sim 10 \mathrm{nM})$, increased the ratio of $\mathrm{CDC} 2$ to $\mathrm{CDC} 1$ among pre$\mu \mathrm{DC}$ progeny in vitro. Higher concentrations further enhanced phenotypic specialization as indicated, e.g., by progressive upregulation of CD101 and Clec9a. These observations support a critical role for RA in the normal development of $\mathrm{cDC}$ and are consistent with a particularly important role for RA in $\mathrm{CDC}$ specialization in the intestines and GALT where vitamin A concentrations are highest. The culture model described here should facilitate future studies of the mechanisms involved.

RA regulated expression of many cDC-subset-specific receptors and differentiation antigens during pre- $\mu \mathrm{DC}$ development into cDC1 and cDC2. Clec9a, an uptake receptor for apoptotic cells, ${ }^{4,5,8}$ and TLR3, a receptor for double-stranded RNA implicated in responses to viruses, are both markers of cDC1. ${ }^{37}$ During in vitro development of $\mathrm{cDC} 1$ from pre- $\mu \mathrm{DC}$, 
RA enhanced Clec9a and was required for expression of TLR3. Similarly, cDC1 from VAD mice have lower TLR3 expression when compared with control mice. Defective TLR3 or Clec9a expression on $\mathrm{CDC1}$ might thus lead to impaired immune responses to RNA viruses or apoptotic cells in VAD states. Our data show that as in the human, CD101 is a specific marker of intestinal $\mathrm{CDC} 2$, and that $\mathrm{RA}$ upregulates it selectively in developing $\mathrm{CDC} 2$ in vitro. Consistent with an RA requirement, intestinal cDC2 from VAD mice expressed little, if any, CD101. Genes for TLR11, Cd300ld, leukocyte inhibitory factor receptor Lifr, triggering receptor expressed on myeloid cells Trem1, and for the lectins Siglec5 and Mgl2, which are selectively expressed by intestinal $\mathrm{CDC} 2$ in vivo, were highly upregulated by RA in developing $\mathrm{CDC} 2$ as well. Although the biological function of many of these RA-regulated receptors remains to be fully clarified, they are likely to control cell-cell interactions, and pathogen and apoptotic cell recognition and signaling activities important to local immune homeostasis and function. CD101 is an immunoregulatory Ig family member implicated in moderation of NF- $\mathrm{KB}$ signaling in $\mathrm{T}$ cells, ${ }^{39}$ and in interleukin10 production and inhibition of $\mathrm{T}$-cell proliferation by cutaneous DCs. ${ }^{40}$ The C-type lectins Clec4a4 (DCIR2, the 33D1 antigen), Siglec5, and Mgl2 are potential cell-cell interaction or pattern recognition receptors. ESAM mediates cell adhesion. Cd300ld and TREM1 are probably DC-activating receptors. ${ }^{41,42}$ Lifr, the leukocyte inhibitory factor receptor, is a member of the type 1 cytokine receptor family with roles in cellular differentiation and regulation of immune function. ${ }^{43}$ Thus, RA controls diverse immune regulatory genes in developing $\mathrm{CDC}$, effects that are likely to contribute to defective and dysregulated immunity in vitamin A deficiency.

Our transcriptomic analyses confirmed that the progeny of pre- $\mu \mathrm{DC}$ cultured with RA align more closely in gene expression to in vivo intestinal $\mathrm{CDC} 1$ and $\mathrm{CDC} 2$ than their counterparts cultured with GM-CSF and Flt3L alone. This was particularly apparent when comparing subsets based on expression of genes differentially expressed by $\mathrm{CDC1}$ vs. CDC2 in vivo. Interestingly, in-vitro-derived $\mathrm{CDC} 2$ deviated more from their in vivo counterparts than $\mathrm{CDC1}$, even when generated in the presence of RA, suggesting that they may be particularly sensitive to and dependent on local environmental influences. Consistent with this, previous studies of gene expression by $\mathrm{cDC}$ from the intestines, skin, lymphoid tissues, and blood showed that $\mathrm{CDC} 2$ from different tissue sites varied much more in gene expression than $\mathrm{CDC} 1 .^{37}$

In addition to controlling $\mathrm{CDC} 1$ and $\mathrm{cDC} 2$ transcriptional programs, RA influences the subset composition of intestinal $\mathrm{cDC}$ and of pre- $\mu \mathrm{DC}$-derived progeny both in vivo and in vitro. These results confirm and extend previous findings showing a role for RA in peripheral $\mathrm{cDC} 2$ development: ${ }^{19,22} \mathrm{VAD}$ mice displayed a selective reduction in peripheral $\mathrm{CDC} 2$ and in splenic $\mathrm{CD} 4{ }^{-} \mathrm{CD} 8{ }^{-} \mathrm{cDC}^{19}{ }^{19}$ This effect on endogenous $\mathrm{cDC} 2$ paralleled the enhancement of $\mathrm{CDC} 2$ generation by RA from pre- $\mu \mathrm{DC}$ both in vitro in culture and in vivo in recipients of transferred pre- $\mu D C$. Moreover, similar to that in VAD mice, mice expressing the dominant-negative RAR403 selectively in
DC had reduced $\mathrm{CDC}$, but not $\mathrm{CDC1}$ numbers, and a decreased cDC2/cDC1 ratio in the SI LP. Although CD11c-RAR403 cDC1 showed aberrant CD207 expression similar to that in VAD mice, changes in $\mathrm{CDC}$ ratios and phenotypic features were less dramatic in DC-RAR403 mice than in VAD or BMS493-treated mice: this may reflect incomplete inhibition of RA signaling by the dominant-negative receptor. ${ }^{44}$ For example, TLR3, which was reduced in SI $\mathrm{CDCl}$ in VAD mice and nearly absent in $\mathrm{CDC1}$ generated in vitro without RA, was retained on $\mathrm{CDC1}$ in $R A R 403^{f l / f l}$ mice. Indeed, we observed a gene dose effect on SI $\mathrm{cDC} 1 / \mathrm{cDC} 2$ ratios when comparing RAR403 fl/fl,$R A R 403^{f / /}$ and WT mice, consistent with incomplete shutdown of RAR transcriptional activity by the dominant-negative RAR403. Together, our results demonstrate a cell-intrinsic role of RA in pre- $\mu \mathrm{DC}$ fate as well as in DC subset phenotypic maturation.. However, they do not preclude an additional role for indirect effects.

Cell-fate determination is controlled by transcription factors. Id2, IRF8, Baft3, Nfil3, and Bcl6 are essential for development of intestinal $\mathrm{cDC} 1,{ }^{37,45}$ whereas IRF4, Notch2, and Blimp1 drive development of intestinal $\mathrm{cDC} 2 .^{37,46,47} \mathrm{RA}$ regulation of the subset-specific expression of some of these critical transcription factors during $\mathrm{cDC}$ development from pre- $\mu \mathrm{DC}$ may contribute to the RA effect on precursor fate, as well as to subsetspecific transcriptional programs. RA suppressed upregulation of the cDC2-associated TF's Irf4 and Prdm1 encoding Blimp1 in $\mathrm{CDC} 1$, which may prevent developing $\mathrm{CDC} 1$ from acquiring a cDC2 phenotype. RA also fine-tuned expression of Bcl6, a TF required for $\mathrm{CDC} 1$ development, by increasing its expression in $\mathrm{cDC} 1$ and decreasing it in $\mathrm{CDC} 2$. These effects result in patterns of expression of subset-determining TF that reflect more accurately those of in vivo $\mathrm{cDC} 1$ and $\mathrm{cDC} 2$. Genes for other transcription factors such as Rel, Stat4, and Zeb2 that are differently expressed by intestinal $\mathrm{cDC} 1$ vs. $\mathrm{CDC} 2$ are also regulated by $\mathrm{RA}$. Whether and to what extent the $\mathrm{CDC2}-$ promoting property of RA and RA control of subset-specific gene expression are mediated by these effects on TF regulation remains to be determined. Analysis of cis-elements in promoters of RA-repressed genes revealed enrichment for NF- $\kappa B$ TFBS motifs, especially in $\mathrm{CDC1}$, and pathway analysis showed RA suppression of genes involved in proinflammatory signaling, a finding consistent with the reported role of RA in inducing or maintaining a tolerogenic phenotype of intestinal DC. ${ }^{22}$ Thus, an additional function of RA signaling may be to suppress activation of $\mathrm{CDC}$ during their initial development from gut-homing precursors. Hivep2, a transcription factor that binds NF- $\kappa$ B TFBS and inhibits transcription, was substantially upregulated by RA in both $\mathrm{CDC} 1$ and $\mathrm{CDC} 2$ in culture and could contribute to the broad suppression of NF-kB target genes.

Taken together, our findings suggest a scenario in which RA regulation of intestinal DC starts in the BM where it positively regulates development of the gut-tropic DC precursor, pre$\mu \mathrm{DC}$. Pre- $\mu \mathrm{DC}$ home to and give rise to both $\mathrm{CDC} 1$ and $\mathrm{CDC} 2$ in the SI. In the gut wall, RA acts directly on pre- $\mu \mathrm{DC}$, likely through regulation of fate-determining transcription factors, to enhance the generation of $\mathrm{CDC} 2$ and to direct gene expression programs in both $\mathrm{CDC} 1$ and $\mathrm{CDC} 2$ that contribute to their 
functional specialization, and their ability to maintain immune homeostasis and coordinate the immune response to invading pathogens.

\section{METHODS}

Mice. C57BL/6.CD45.2 (B6.CD45.2), C57BL/6.CD45.1 (B6.CD45.1), and $\mathrm{BALB} / \mathrm{c}$ mice were originally purchased from Jackson Laboratory (Bar Harbor, ME), and were maintained and bred in specific pathogenfree conditions in the animal facility at the Veterans Affairs Palo Alto Health Care Systems. To generate B16/Flt3L-injected mice, five million B16/Flt3L cells were injected subcutaneously near the neck and animals were killed 11-14 days later. All animals were used in accordance with guidelines set forth by the animal committee of the Veterans Affairs Palo Alto Health Care Systems. VAD and control mice were generated as described. ${ }^{17}$ Short-term VAD mice were generated by putting newly weaned mice (3-4 weeks) on VAD or control diet for 1-3 months. In some experiments, mice were intraperitoneally injected with BMS493 ( $25 \mathrm{~mm}$ in dimethyl sulfoxide) at $1 \mu \mathrm{l}$ per gram of weight in $100 \mu \mathrm{l}$ of olive oil. Control animals received the same amount of dimethyl sulfoxide in olive oil. All trans-RA was made into suspension in olive oil at $25 \mathrm{mg} \mathrm{ml}^{-1}$ and injected intraperitoneally at $125 \mu \mathrm{g}$ per gram of weight; control animals received olive oil. AM580 was dissolved in dimethyl sulfoxide at a concentration of $20 \mathrm{mg} \mathrm{ml}^{-1}$ and injected intraperitoneally at $1 \mu \mathrm{l}$ per gram of weight in $100 \mu \mathrm{l}$ of olive oil; control animals received the same amount of dimethyl sulfoxide in olive oil. Animals were injected every $24 \mathrm{~h}$ for 5 days.

Flow cytometry. Samples (single-cell suspensions) were first blocked with fluorescence-activated cell sorting buffer (Hank's balanced salt solution with $2 \%$ fetal calf serum) containing $100 \times$ dilution of antibody against mouse Fc $\gamma \mathrm{III} / \mathrm{II}$ receptor (BD Bioscience, San Jose, $\mathrm{CA}$ ) and rat serum to prevent nonspecific binding of monoclonal antibodies. The following antibodies were used for staining: CD3-PECy7/CD3-Biotin (145-2C11), CD19-PECy7/CD19-biotin (ID3), NK1.1-PECy7/NK1.1-biotin (PK136), CD49b-Biotin(DX-5), Ly6G-Biotin (1A8), Ter-119-biotin(Ter-119), B220-PECy7/B220-Biotin/B220-PerCPCy5.5 (RA3-6B2), MHCII-AF700/MHCII-FITC(M5/ 114.15.2)/MHCII-Biotin (2G9), CD11c-PB (N418), $\alpha 4 \beta 7-A P C / \alpha 4 \beta 7-P E$ (DATK32), CCR9-APC/CCR9-PE/CCR9-FITC (242503), CD103-PE/ CD103-APC(M290), CD11b-AF700 (M1/70), CD8 $\alpha$-PE (53-6.7), CD45.1-PerCPCy5.5/CD45.1-APC, CD45.2-FITC/CD45.2-PerCPCy5.5 (RA3-6B2), CD135-PE/CD135-PerCP-EfluorF710 (A2F10), CD4AF700(RM4-5), Sirp $\alpha$-FITC/Sirp $\alpha$-PerCP-eFluor710 (P84), TLR3-PE (11F8), Clec4a4-PE/Clec4a4-Biotin (33D1), CD101-PE (Mousei101), Clec9a-PerCP-eFluor710 (44D2), and Langerin-FITC. All experiments analyzing $\mathrm{cDC}$ subsets included pre-gating on live, $\mathrm{CD} 3 \mathrm{e}^{-}, \mathrm{CD} 19^{-}$, NK1.1 ${ }^{-}, \mathrm{MHCII}^{+}$, and $\mathrm{CD} 11 \mathrm{c}^{+}$.

\section{Cell isolation from tissues}

Cell sorting. Pre- $\mu \mathrm{DC}$ and pre-cDC were sorted from B16/Flt3L treated mice. ${ }^{11} \mathrm{BM}$ cells were isolated as described above and enriched by magnetic activated cell sorting using the pan-DC kits from Miltenyi (San Diego, CA). The cells were then sorted on Aria II or III (BD) for Lineage (CD3, CD19), and NK1.1)-CD11 $\mathrm{c}^{\text {int }} \mathrm{B} 220^{+} \alpha 4 \beta 7^{+} \mathrm{CCR}^{-}$ pre- $\mu \mathrm{DC}$ and Lineage (CD3, CD19, NK1.1, and B220)-CD11 $c^{\text {int }} \mathrm{MH}-$ CII-Sirpa ${ }^{+}$pre-cDC.

Adoptive transfer. Sorted pre- $\mu \mathrm{DC}\left(0.5-1 \times 10^{6}\right.$; CD45.2 or CD45.1) were injected retro-orbitally into congenic recipients (CD45.1 or CD45.2). Recipient animals were killed 5-7 days after transfer.

In vitro culture. Pre- $\mu \mathrm{DC}$ were sorted from $\mathrm{BM}$ from Flt3L-treated mice and cultured 0.5 million cells per $\mathrm{ml}, 200 \mu \mathrm{l}$ per well in flatbottom 96-well plate or $2 \mathrm{ml}$ per well in 6-well plate in complete Iscove's modified Deulbecco's media (10\% delipidated fetal calf serum, $1 \times$ penicillin/streptomycin) supplemented with $100 \mathrm{ng} \mathrm{ml}^{-1}$ recombinant Flt3L, $10 \mathrm{ng} \mathrm{ml}^{-1}$ recombinant GM-CSF and RA of indicated concentration. Media were changed on day 3 .

\section{Analysis of aldehyde dehydrogenase activity was as described}

Microarray. Total RNA was isolated from in-vitro-derived $\mathrm{cDC} 1$ and cDC2 in the presence or the absence of $100 \mathrm{~nm}$ RA using phenolchloroform extraction method provided by Immgen (http://immgen. org). ${ }^{11}$ RNA integrity was determined using an Agilent Bioanalyzer (Stanford PAN Facility, Stanford, CA). Intact total RNA from each sample was used for amplification, labeling, and hybridization by expression analysis. Samples were hybridized on a GeneChip mouse Gene 1.0 ST Array (Affymetrix, Santa Clara, CA). GeneSpring GX 12.6 (Agilent Technologies, Santa Clara, CA) software and the Partek Genomic Suite (version 6.6, St Louis, MO) were used to process and analyze the microarray data.

Statistical analysis. The statistical significance of differences between two sets of data was assessed by Student's $t$-test unless stated otherwise.

SUPPLEMENTARY MATERIAL is linked to the online version of the paper at http://www.nature.com/mi

\section{ACKNOWLEDGMENTS}

We thank L. Rott for assistance with flow cytometry and cell sorting. The B16 melanoma cell line stably transfected with murine Flt3L was a kind gift from G. Dranoff, Dana-Farber Cancer Institute, Boston, MA. RAR403fl/fl mice are a generous gift from Dr. Shanthini Sockanathan (Johns Hopkins School of Medicine). R.Z. is a recipient of the National Science Scholarship awarded by the Agency for Science, Technology And Research, Singapore. M.B. is funded by the German Research Foundation (DFG) grant BS56/1-1. K.L. was supported by fellowships from the German Research Foundation (DFG), the Crohn's and Colitis Foundation of America, and an ITI Young Investigator Award from Stanford. M.L. is a recipient of a senior fellowship from the Crohn's and Colitis Foundation, and was a fellow under the NIH Training Grant Al07290. This work was supported in part by NIH grants R01 Al093981 and R37 Al047822 to E.C.B.

\section{TRANSCRIPT PROFILING}

Accession number of repository for expression microarray data: GSE 68399

\section{AUTHOR CONTRIBUTIONS}

R.Z. designed and performed experiments, analyzed and interpreted data, and wrote the manuscript. M.B. performed experiments, analyzed and interpreted data, and edited the manuscript. K.L. and M.L. performed experiments. E.C.B. directed the study and wrote the manuscript. All authors reviewed and commented on the manuscript.

\section{DISCLOSURE}

The authors declare no conflict of interest.

(c) 2016 Society for Mucosal Immunology

\section{REFERENCES}

1. Gottschalk, C. et al. Batf3-dependent dendritic cells in the renal lymph node induce tolerance against circulating antigens. J. Am. Soc. Nephrol. 24, 543-549 (2013).

2. Crozat, $\mathrm{K}$. et al. Cutting edge: expression of XCR1 defines mouse lymphoid-tissue resident and migratory dendritic cells of the CD8alpha + type. J. Immunol. 187, 4411-4415 (2011).

3. Bachem, A. et al. Expression of XCR1 characterizes the Batf3-dependent lineage of dendritic cells capable of antigen cross-presentation. Front. Immunol. 3, 214 (2012).

4. Zhang, J.G. et al. The dendritic cell receptor Clec9A binds damaged cells via exposed actin filaments. Immunity 36, 646-657 (2012). 
5. Zelenay, S. et al. The dendritic cell receptor DNGR-1 controls endocytic handling of necrotic cell antigens to favor cross-priming of CTLs in virusinfected mice. J. Clin. Invest. 122, 1615-1627 (2012).

6. Sancho, D. et al. Identification of a dendritic cell receptor that couples sensing of necrosis to immunity. Nature 458, 899-903 (2009).

7. Poulin, L.F. et al. DNGR-1 is a specific and universal marker of mouse and human Batf3-dependent dendritic cells in lymphoid and nonlymphoid tissues. Blood 119, 6052-6062 (2012).

8. Iborra, S., Izquierdo, H.M., Martinez-Lopez, M., Blanco-Menendez, N., Reis e Sousa, C, \& Sancho, D. The DC receptor DNGR-1 mediates crosspriming of CTLs during vaccinia virus infection in mice. J. Clin. Invest. 122, 1628-1643 (2012).

9. Caminschi, I. et al. Antibody responses initiated by Clec9A-bearing dendritic cells in normal and Batf3(-/-) mice. Mol. Immunol. 50, 9-17 (2012).

10. Liu, K. et al. In vivo analysis of dendritic cell development and homeostasis. Science 324, 392-397 (2009).

11. Zeng, R. et al. Retinoic acid regulates the development of a gut-homing precursor for intestinal dendritic cells. Mucosal. Immunol. 6, 847-856 (2013).

12. Jaensson-Gyllenback, E. et al. Bile retinoids imprint intestinal CD103+ dendritic cells with the ability to generate gut-tropic T cells. Mucosal. Immunol. 4, 438-447 (2011).

13. Hall, J.A., Grainger, J.R., Spencer, S.P. \& Belkaid, Y. The role of retinoic acid in tolerance and immunity. Immunity 35, 13-22 (2011).

14. Mora, J.R. et al. Generation of gut-homing IgA-secreting B cells by intestinal dendritic cells. Science 314, 1157-1160 (2006).

15. Sun, C.M. et al. Small intestine lamina propria dendritic cells promote de novo generation of Foxp3 T reg cells via retinoic acid. J. Exp. Med. 204, 1775-1785 (2007).

16. Hill, J.A. et al. Retinoic acid enhances Foxp3 induction indirectly by relieving inhibition from CD4 + CD44hi Cells. Immunity 29, 758-770 (2008).

17. Iwata, M., Hirakiyama, A., Eshima, Y., Kagechika, H., Kato, C. \& Song, S.Y. Retinoic acid imprints gut-homing specificity on T cells. Immunity 21, 527-538 (2004).

18. Beijer, M.R., Molenaar, R., Goverse, G., Mebius, R.E., Kraal, G. \& den Haan, J.M. A crucial role for retinoic acid in the development of Notchdependent murine splenic CD8- CD4- and CD4 + dendritic cells. Eur. J. Immunol. 2013)43, 1608-1616 (2013).

19. Klebanoff, C.A. et al. Retinoic acid controls the homeostasis of pre-cDCderived splenic and intestinal dendritic cells. J. Exp. Med. 210, 1961-1976 (2013).

20. Molenaar, R. et al. Expression of retinaldehyde dehydrogenase enzymes in mucosal dendritic cells and gut-draining lymph node stromal cells is controlled by dietary vitamin A. J. Immunol. 186, 1934-1942 (2011).

21. Yokota, A. et al. GM-CSF and IL-4 synergistically trigger dendritic cells to acquire retinoic acid-producing capacity. Int. Immunol. 21, 361-377 (2009).

22. Iliev, I.D., Mileti, E., Matteoli, G., Chieppa, M. \& Rescigno, M. Intestinal epithelial cells promote colitis-protective regulatory T-cell differentiation through dendritic cell conditioning. Mucosal. Immunol. 2, 340-350 (2009).

23. Chang, S.Y. et al. Lack of retinoic acid leads to increased langerinexpressing dendritic cells in gut-associated lymphoid tissues. Gastroenterology 138, 1468-1478 (2010). 1478 e1461-1466.

24. Hashimoto, D., Miller, J. \& Merad, M. Dendritic cell and macrophage heterogeneity in vivo. Immunity 35, 323-335 (2011).

25. Villablanca, E.J. et al. MyD88 and retinoic acid signaling pathways interact to modulate gastrointestinal activities of dendritic cells. Gastroenterology 141, 176-185 (2011).

26. Mowat, A.M. \& Agace, W.W. Regional specialization within the intestinal immune system. Nat. Rev. Immunol. 14, 667-685 (2014).
27. Denning, T.L. et al. Functional specializations of intestinal dendritic cell and macrophage subsets that control Th17 and regulatory Tcell responses are dependent on the T cell/APC ratio, source of mouse strain, and regional localization. J. Immunol. 187, 733-747 (2011).

28. Helft, J., Ginhoux, F., Bogunovic, M. \& Merad, M. Origin and functional heterogeneity of non-lymphoid tissue dendritic cells in mice. Immunol. Rev. 234, 55-75 (2010).

29. Rajaii, F., Bitzer, Z.T., Xu, Q. \& Sockanathan, S. Expression of the dominant negative retinoid receptor, RAR403, alters telencephalic progenitor proliferation, survival, and cell fate specification. Dev. Biol. 316, 371-382 (2008).

30. Murphy, K.M. Comment on "Activation of beta-catenin in dendritic cells regulates immunity versus tolerance in the intestine". Science 333, 405 (2011).

31. Inaba, K. et al. Generation of large numbers of dendritic cells from mouse bone marrow cultures supplemented with granulocyte/macrophage colony-stimulating factor. J. Exp. Med. 176, 1693-1702 (1992).

32. Mayer, C.T. et al. Selective and efficient generation of functional Batf3dependent CD103 + dendritic cells from mouse bone marrow. Blood 124, 3081-3091 (2014).

33. Naik, S.H. et al. Cutting edge: generation of splenic CD8 + and CD8dendritic cell equivalents in Fms-like tyrosine kinase 3 ligand bone marrow cultures. J. Immunol. 174, 6592-6597 (2005).

34. Bogunovic, M. et al. Origin of the lamina propria dendritic cell network. Immunity 31, 513-525 (2009).

35. Heng, T.S. \& Painter, M.W. The Immunological Genome Project: networks of gene expression in immune cells. Nat. Immunol. 9, 1091-1094 (2008).

36. Fujikado, N. et al. Dcir deficiency causes development of autoimmune diseases in mice due to excess expansion of dendritic cells. Nat. Med. 14, 176-180 (2008).

37. Watchmaker, P.B. et al. Comparative transcriptional and functional profiling defines conserved programs of intestinal $D C$ differentiation in humans and mice. Nat. Immunol. 15, 98-108 (2014).

38. Chen, E.Y. et al. Enrichr: interactive and collaborative HTML5 gene list enrichment analysis tool. BMC Bioinformatics 14, 128 (2013).

39. Soares, L.R., Tsavaler, L., Rivas, A. \& Engleman, E.G. V7 (CD101) ligation inhibits TCR/CD3-induced IL-2 production by blocking Ca2 + flux and nuclear factor of activated T cell nuclear translocation. J. Immunol. 161, 209-217 (1998).

40. Bouloc, A., Bagot, M., Delaire, S., Bensussan, A. \& Boumsell, L. Triggering CD101 molecule on human cutaneous dendritic cells inhibits $T$ cell proliferation via IL-10 production. Eur. J. Immunol. 30, 3132-3139 (2000).

41. Bouchon, A., Facchetti, F., Weigand, M.A. \& Colonna, M. TREM-1 amplifies inflammation and is a crucial mediator of septic shock. Nature 410, 1103-1107 (2001).

42. Enomoto, Y. et al. Characterization of leukocyte mono-immunoglobulinlike receptor 7 (LMIR7)/CLM-3 as an activating receptor: its similarities to and differences from LMIR4/CLM-5. J. Biol. Chem. 285, 35274-35283 (2010).

43. Weber, M.A. et al. Endogenous leukemia inhibitory factor attenuates endotoxin response. Lab. Invest. 85, 276-284 (2005).

44. Caton, M.L., Smith-Raska, M.R. \& Reizis, B. Notch-RBP-J signaling controls the homeostasis of CD8- dendritic cells in the spleen. J. Exp. Med. 204, 1653-1664 (2007).

45. Edelson, B.T. et al. Peripheral CD103 + dendritic cells form a unified subset developmentally related to CD8alpha + conventional dendritic cells. J. Exp. Med. 207, 823-836 (2010).

46. Persson, E.K. et al. IRF4 transcription-factor-dependent CD103(+) $\mathrm{CD} 11 \mathrm{~b}(+)$ dendritic cells drive mucosal T helper 17 cell differentiation. Immunity 38, 958-969 (2013).

47. Schlitzer, A. et al. IRF4 transcription factor-dependent CD11b + dendritic cells in human and mouse control mucosal IL-17 cytokine responses. Immunity 38, 970-983 (2013). 